\title{
Assessment for the Evaluation of E-Learning and Teaching by the Quality Matter Standards Post COVID-19
}

\author{
Hind Abdelmoneim Khogali ${ }^{1}$ \\ ${ }^{1}$ College of Architecture Engineering and Digital Design, Dar Al Uloom University, Riyadh City, Saudi Arabia \\ Correspondence: Hind Abdelmoneim Khogali, College of Architecture Engineering and Digital Design, Dar Al \\ Uloom 7 University, Riyadh City, Saudi Arabia. ORCID iD: https://orcid.org/0000-0002-0738-4583
}

Received: May 8, 2021

Accepted: June 1, 2021

Online Published: June 4, 2021

doi:10.5539/mas.v15n4p1

URL: https://doi.org/10.5539/mas.v15n4p1

\begin{abstract}
On 18 March, the WHO announced that COVID-19 was a global pandemic, and the Ministry of Health instituted a COVID-19 lockdown. After the period of restrictions ended, blended learning was initiated at the universities.

The research aims to evaluate the responses of students, teachers, and quality units in the teaching and learning process by Quality Matter standards. The survey was constructed using a Google form. The research recorded positive data in most of the Quality Matter Standards (QM) in Architecture Engineering Program applied by $95 \%$. Some weakness points were identified $5 \%$ and are discussed in this paper. The results by (QM) St1 (2.7/3), St2 (2.6/3), St3 (2.6/3), St4 (2.6/3), St5 (2.6/3), St6 (2.5/3), St7 (2.6/3), St8 (2.7/3). General conclusions are added for teachers to be applied to e-learning education.
\end{abstract}

Keywords: assessment of quality matter, higher education, e-learning, post-COVID-19, data use, student management system, quality matter standards checklist

\section{Introduction}

The Quality Matter is an international online system for learning that helps institutions achieve their goals with well-conceived, well-designed, well-presented courses and programs and enables them to be certified by quality assurance organizations (Matter, 2020). Since the lockdown 2020, most universities applied the e-learning on the second semester 2020. During the new academic year, the university is going into blending teaching and learning, the practical courses in campus and the theoretical courses online.

The problem of the research that the e-learning was applied on the second semester 2020 was not planned, and the teachers were not trained. That's why the QM has been applied by the university to improve the quality of e-learning and teaching during the academic year 2020-2021, in Architecture Engineering courses the results were recorded for September 2020-1 semester, the results is distributed to the faculty member for improvement plan.

The objectives of this research; to evaluate Architecture courses using a Quality Matter checklist in an E-Learning system; to improve the course's learning outcomes results; to record the weakness points for greater improvement; to compare the results of different stockholders (Quality Unit-Students) for greater improvement.

\subsection{Research Hypotheses}

1) Student Learning System (LMS) is applying the Quality Matter Standards

2) The Architecture courses pass the evaluation

3) There is an improvement plan to develop the e-courses in Architecture program

\subsection{Literature Review}

IEA (2007) published a report about the role of international engineering alliances. Their focus objectives included consistent improvement of standards and mobility, defining standards of education and professional competence, assessment of education accreditation and evaluation of competence, and participation in activities that are driven by the engineering profession.

The report expanded the graduate attributes by the Washington Accord. They categorized what graduates should know, the skills they should demonstrate, and the attitudes they should possess, such as problem-solving, 
communication skills, writing different reports, designing documentation, making effective presentations, and knowledge of engineering practice (technology) in the practice areas and in the engineering discipline. Shattuck (2019) applied the quality matter standards on the KG-12 and recorded the results on the learning outcome of the research. The results show that standards 4, 5, 6, and 7 had outstanding results because of student engagement in activities such as research and interaction with peers or teachers.

ABET (2019) published a report about the criteria of accreditation for engineering programs, including student program education, student outcomes, continuous improvement, curriculum, facilities, and faculty. In criteria 1: The program must have enforced policies for accepting both new and transfer students, appropriate academic credit must be awarded for courses taken at other institutions, appropriate academic credit must be awarded for work. Also, the program must have enforced procedures to ensure that students who graduate meet all graduation requirements, and these metrics should be documented. In criterion 7, the facilities should be applied in classes, offices, and laboratories, and associated equipment.

ETEC (2020) published national engineering learning outcomes. The National Engineering Learning Outcomes shall be aligned with the NQF descriptions of the learning outcomes at the bachelor's degree level. The three focus domains in learning outcomes include:

- Knowledge

- Skills

- Values

Table 1. Comparison between international, national and program learning outcomes

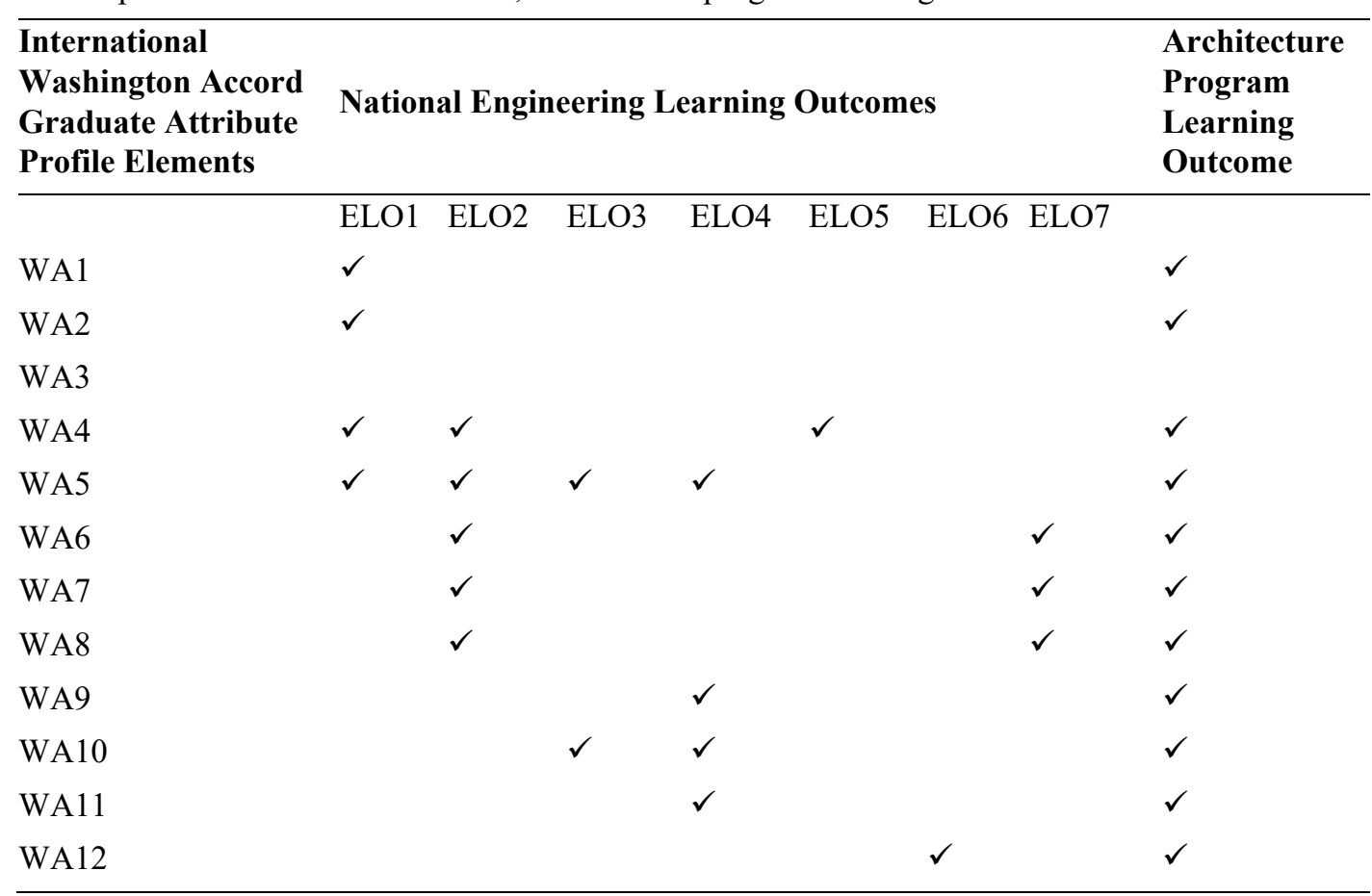

Source: (ETEC, 2020).

(QM, 2019) provided a report about virtual support for teaching the quality matters to create and provide superior courses for students and schools that are the standard for all learning in the state of Arkansas and nationwide. The Quality Matter QM course review process allows the students to receive a much clearer and more consistent course, which is vital to reaching their goal. QM (quality matter, 2020) published a white paper about administrative digital accessibility at the institutional level. Institutes should provide regular support for digital accessibility, such as web accessibility, online learning, budgets, improved technical skills for students and teachers and administrative staff and policies for technical and digital use. The survey should be distributed to users to received responses about technical support.

QM (Quality Matter, 2021) published the quality matter checklist, see page 4). Figure 1: Quality Matter standards. Source: Quality Matter.org. The latest research papers discussed E-Learning during COVID-19; Mammadova, I. (2020) discussed using the new technology in teaching the design such as divided the class into 
groups and get feedback from them, operate the platform, and learn the students how to deal with a real-life. Daniel C. (2020). discussed in his book innovation ideas in E-teaching and E-Learning during COVID-19; the book explained different innovation ideas to be applied in the online teaching such as develop the platform and develop the courses during 2020 is becoming crucial. Besides Mseleku, Z. (2020) discussed the start of the transformation into online teaching and learning during COVID-19 and highlight that higher education may have transformed and moved to online. Ghobrini (2020) discussed in his research paper using YouTube and Facebook as teaching technology in E-Learning and E-Teaching in Grammar during COVID-19. Sadaf, A. (2019) the research paper applied the quality matter on the impact of the students in University of North Carolina Charlotte the results help the researcher to develop the learning outcome. Alizadeh, M. (2019) the researcher reflects the experience in Japan with the blending learning and applied the QM for evaluating the learning outcome the results shoe failure 70/99 the orientation from the reviewer advice to re-evaluate and improvement should be done. Jassim, L. L. (2020) the researcher discussed Information and Communication Technologies (ICTs) in Iraq in the last year in the E-Learning and teaching. Sireesha1, N. (2020) the researcher highlights the use of digital technology in studying the MBA in India the results recommend using LMS to build trust of the students. Also, Sharma, A., (2017) the researcher highlighted using of different technologies such as virtual classes, virtual labs in e-learning and teaching. Khogali, Hind (2020) the researcher discussed the effect of COVID 19 on teaching and learning in architecture colleges and the blending learning during the lockdown in 2020.highlighted the important of training the teachers and improve the Wi-Fi in the university.

The last literature in the field of the study: Goda (2020) highlighted the importance of Technology and online learning platforms have become an essential part of the educational process, learner support, workshops, and interactive learning. Oyediran (2020) highlighted some problems facing least developed countries such as in Nigeria vis-_a-vis their socio-economic factors and limitations encountered and poor infrastructure and networking. Fauzi (2020) highlighted some problems facing the online teaching in West Java such as availability of facilities, network and internet usage, planning, implementation, and evaluation of learning, and collaboration with Parents and highlighted the importance of the policies and research to compare the experience of online teaching with others to find solutions. Sultana (2020) highlighted the point that the e-learning should be available for all students in the country, require high skill, be independent, large groups, smart learning. Vaid (2020) highlighted the importance of using the artificial intellegent in e-Learning and accuracy of deep learning. Education, Sweden National Agency for Higher. 2008. This model has been developed using analyzes of policy documents, networks and development projects initiated within the framework of European cooperation. Karin J. (2019) highlighted the point the effect of assessment, interpretation, the credibility of assessment, on e-learning the students response is positive to these variables. Mark, Th. (2020) discussed the effect of COVID-19 on education in Saudi Arabia and highlight that most of the schools change to online teaching and learning, the need of the platform, strong internet, mobile, computer devices all are available in Saudi Arabia by $90 \%$ and this succeeds the e-learning education in Saudi Arabia and, Also, Mark, Th. (2021) highlighted e-learning and teaching in Saudi Arabia. Mark, Th. discussed the effect of COVID-19 on public health, economy, and migration in Saudi Arabia, these areas could be an area of future research studies.

The researcher believe that each country has own experience in the e-learning according to the available technologies, and can take the benefits of other countries experience.

\subsection{The Procedures Applied by the College to Achieve QM Standards}

\subsubsection{Develop the Course Syllabus}

During 2020-2 semester college of architecture applied the total grade distribution: $60 \%$ for the continuous assessment and $40 \%$ for the final exam.

\subsubsection{Develop the Course Learning Outcomes}

(Khogali, H. 2020) stated that The College of Architecture Engineering developed the course learning outcomes according to in the National Center of Academic Accreditation and Evaluation (NCAAA).

\subsubsection{Develop the Students' Learning and Management System (LMS)}

The Quality Unit provided a comprehensive workshop to the University Staff. The workshop explained the eight standards of E-Learning and stated that faculty members should develop his/her LMS page, everything should be clear for the students, and the course syllabus, course specifications, lectures, online exams, and student manual should be uploaded. Figure 2: Screenshot from the university LMS. 


\subsubsection{Develop the Course Report}

The university follows the NCAAA template. The last update has been applied, consisting of the NAGF and 3 main domains of learning outcomes, including knowledge, skills, and values.

\subsubsection{Develop the Course Learning Outcomes}

History of Architecture course (ARC213)

Khogali, H. (2020) discussed the course history of architecture learning out come

Environmental Control (ARC404)

Khogali, H. (2020) discussed the learning outcomes in Environmental control course

Design Studio One (ARC211)

Knowledge is achieved by letting the student draw and design warm-up exercises in bedrooms, master bedrooms, and flats for students living in the UK using Neufert for Architecture Data.

Skills are achieved through case study analysis, heritage case study analysis, and modern case studies. The design concept develops the student's critical thinking ability to design a Modern Saudi Villa using modern design projects in villas as inspiration.

The design project is developed. Besides, Discussions take place in multiple juries.

Blended learning is used (50\% of learning is on the university campus, $50 \%$ is online using Microsoft Teams).

Value: is achieved by teaching the student the responsibility of uploading their assignments in the LMS on time. Additionally, teamwork is used for case studies and site analyses.

Theory of Architecture one (ARC302)

Knowledge is evaluated in the midterm, short exam, and final exam.

Cognitive skills are achieved by five weekly assignments, analysing case studies in the history of the Middle Ages and prehistoric architecture, and comparing between different eras.

Interpersonal skills are achieved by uploading all the assignments in LMS and attending the virtual class at the appropriate time.

Communication skills are achieved by encouraging the students to discuss their assignments through virtual classes during lectures. The discussion is directed by the teacher and sometimes between the students in groups.

Psychomotor skills. The sketch is submitted in the LMS. The teaching method employs PowerPoint presentations.

\subsubsection{Comprehensive Workshops}

Workshops are held by the university about e-learning and the quality matter standards. The workshop explains the eight standards.

\section{Method}

This research is quantitative research based on a survey distributed to students in architecture colleges. The survey tool was used to record their responses to teaching and learning in the virtual classes. It was constructed using Google Forms and sent to 73 students after they completed their final exams between 30/11/2020 and 30/12/2020. The survey contains 43 questions, including 8 standards of Quality Matter in Figure 1, general information, the responses from the students about design studios and theocratical courses, the technical problems facing the students during virtual classes, and the responses of students towards the method of assessment.

A comparison between the university experience and Alyamamaha and Efatt universities in the 17-NCAAA learning out comes was done by the DAU quality unit in the 2020-2 semester, the performance range between $3 / 5$ to $4 / 5$.

This research developed the Quality matter checklist to evaluate in five points instead of three points of evaluation. 


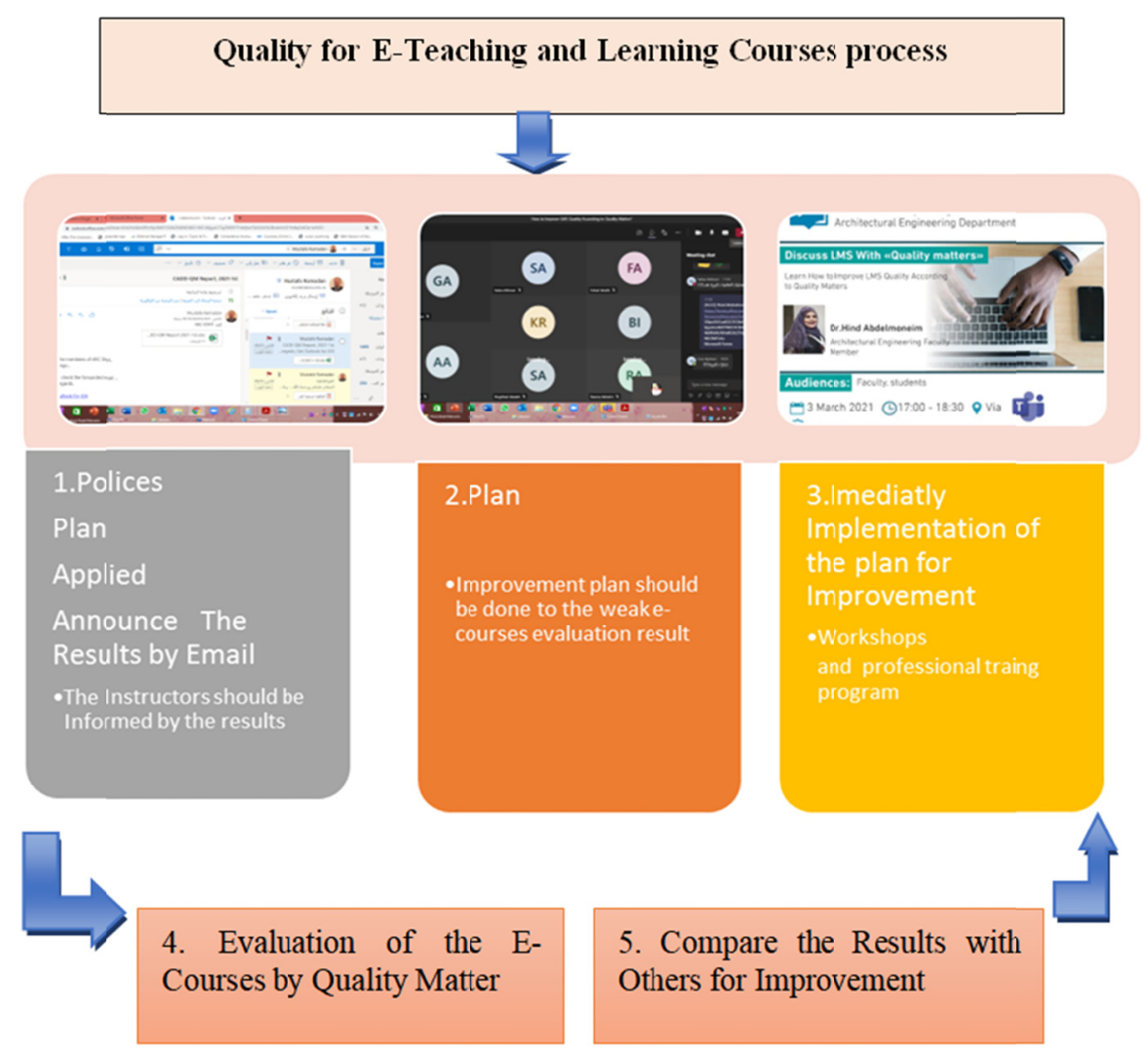

Figure 1. The e-learning courses Quality matter evaluation process. Source: designed by the researcher

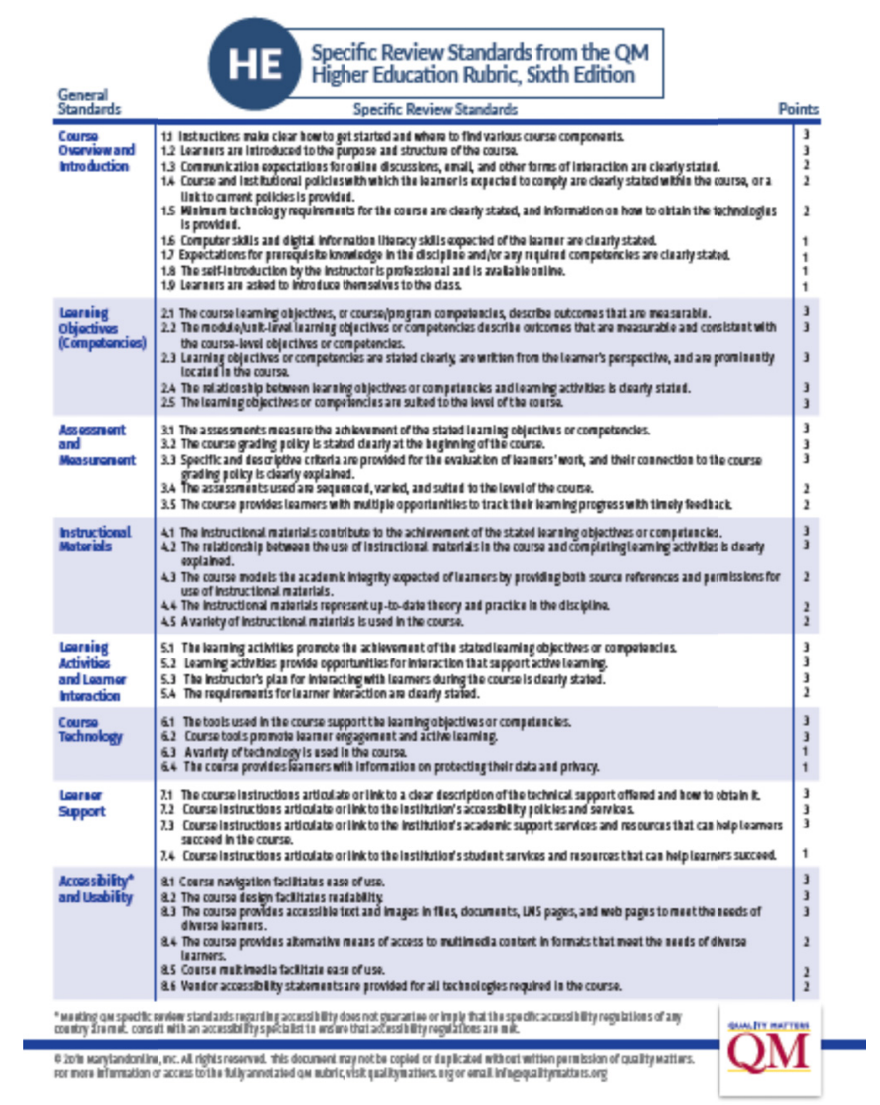

Figure 2. Quality Matter standards. Source: Quality Matter.org 


\section{Results}

The results record from the distributed survey to all the students in the architecture program 2020-2021-1 semester. The evaluation method for each category.

The number of points achieved /Total Number of points, Strength points, to record the weakness points. All the standard results records in the followings:

\subsection{Standard 1: Course Overview}

It was achieved by $90 \%$ (2.8/3) in the four courses Environmental Control (ARC404), History of Architecture (ARC213), Theory of Architecture (ARC302), and Design Studio (ARC211). The learners answered standard points 1.1, 1.3, 1.5, and 1.6 positively, and the course overview achieved QM standard 1. The learners highlighted some weak points, such as substandard point (1.4.) the policies are not available Substandard point (1.2.) Computer skills and digital information literacy skills expected of the learner are clearly stated. (1.7) the teacher should give more explanation (1.8) the students should know of the present. Figure 3 shows the results of standard 1.

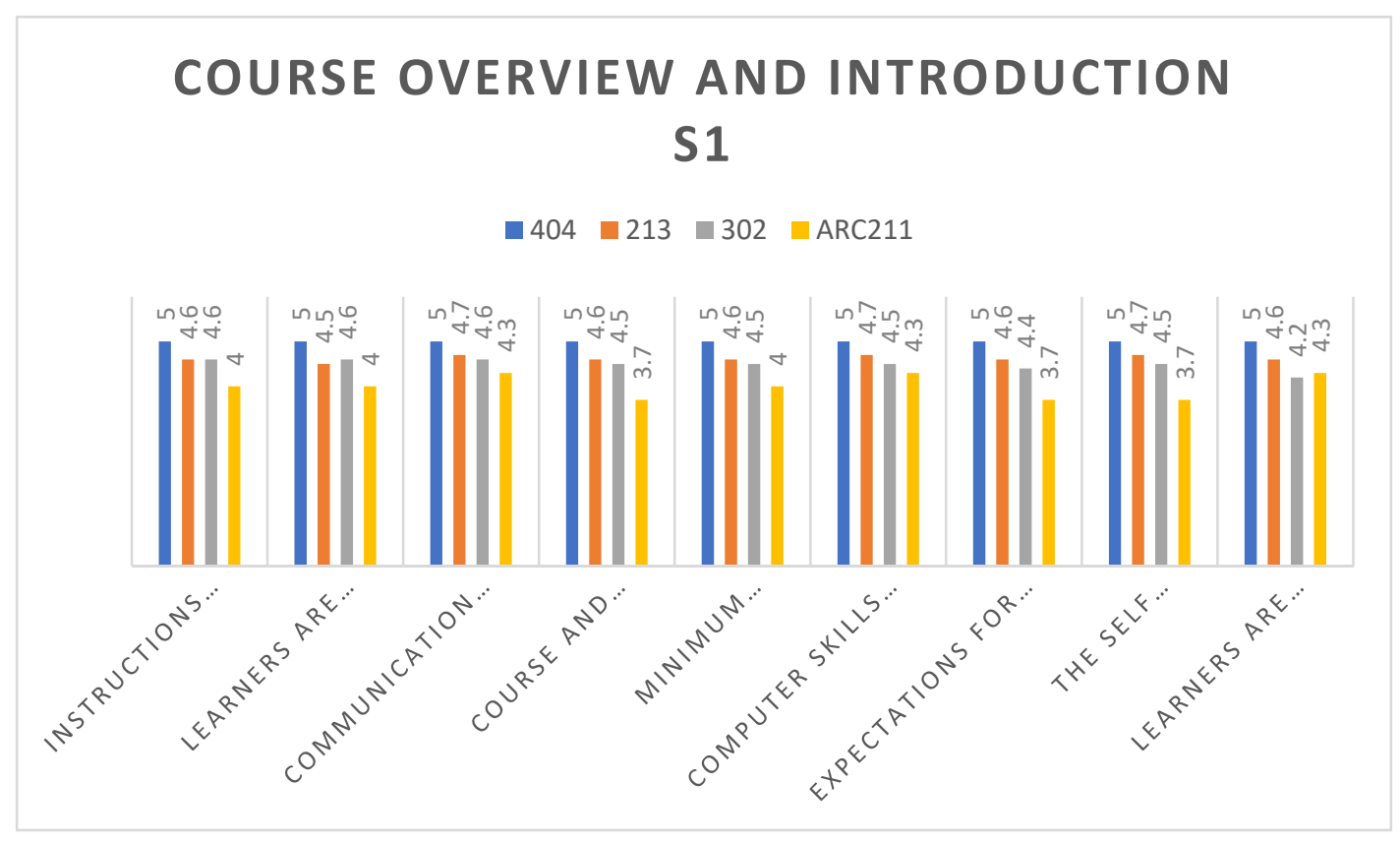

Figure 3. Evaluation, of the courses ARC404, 213, 302, 211 Standard 1 in Quality Matter

\subsection{Standard 2: Learning Objectives}

(Competencies) was achieved by 87\% (2.6) in the four courses (ARC404, ARC213, ARC302, and ARC211). The learners answered standard points 2.1, 2.2, 2.3, and 2.4 positively, which means that the courses achieved QM standard 2 in QM. The learners highlighted some weak points: Substandard point (2.5), the learning objectives or competencies are suited to the level of the course. Figure 4 shows the evaluation of Standard 2. 


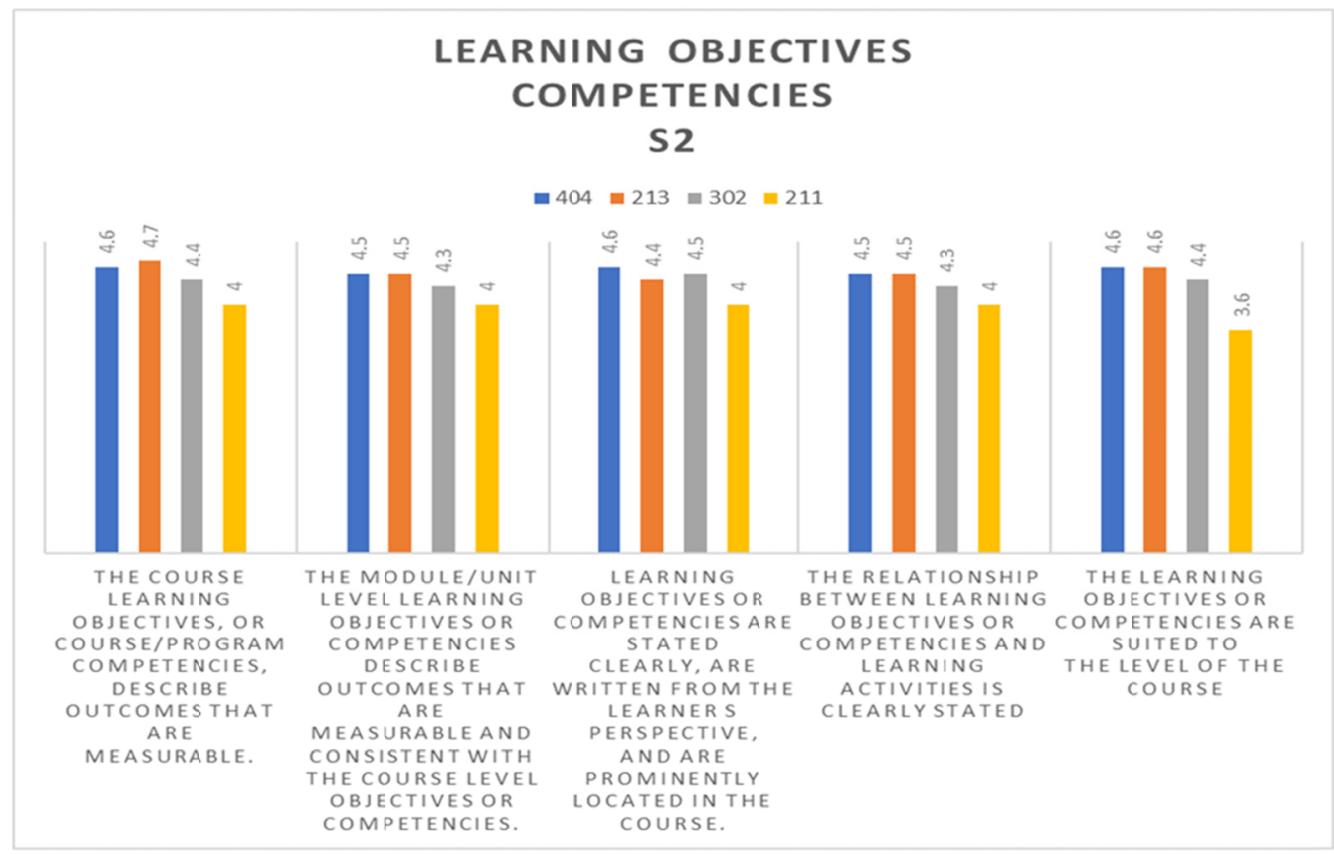

Figure 4. Evaluation, of course, ARC404, ARC213, ARC302, ARC211 Standard 2 in Quality Matter

\subsection{Standard 3: Assessment and Measurement}

It was achieved by $86 \%(2.6 / 3)$ in the four courses (ARC404, ARC213, ARC302, and ARC211). The learners answered standard points 3.1 and 3.4 positively, which means that these two points achieved QM standard 3. The learners highlighted some weak points, such as:

Substandard point (3.2), the course grading policy is stated clearly at the beginning of the course (33\%).

Substandard point (3.3), specific and descriptive criteria are provided for the evaluation of learners' work, and their connection to the course grading policy is clearly explained (33\%). Figure 5 shows the evaluation of standard 3.

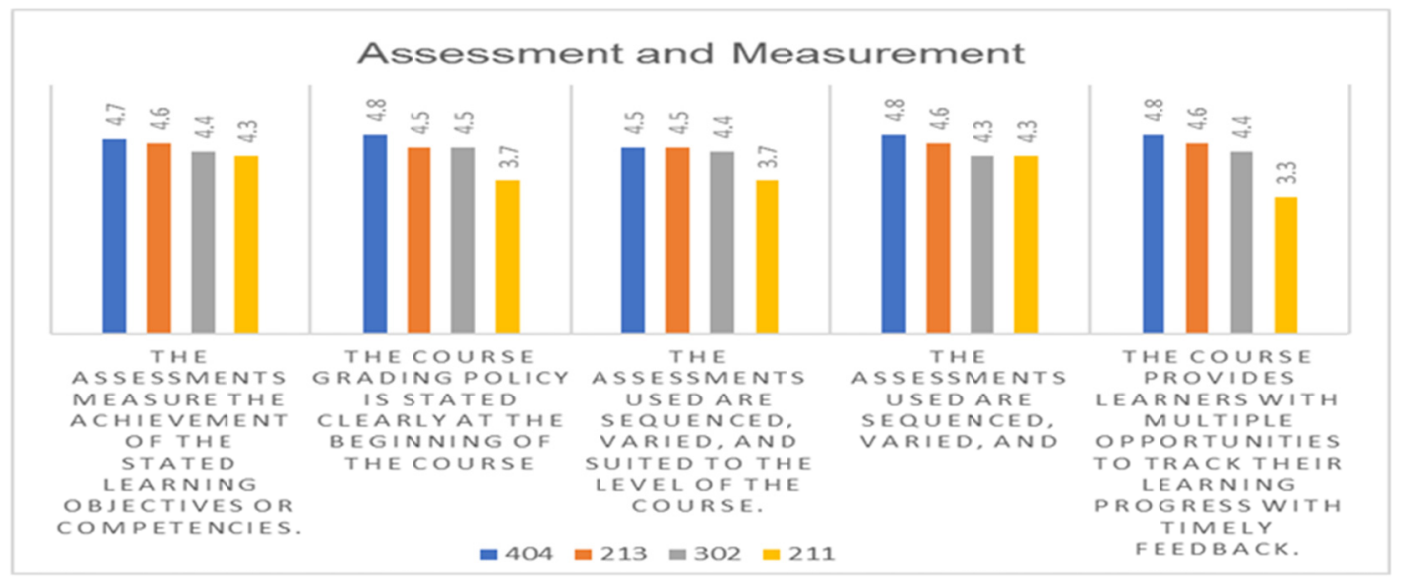

Figure 5. Evaluation of courses ARC404, ARC302, ARC213, and ARC211 for standard 3 in Quality Matter

\subsection{Standard 4: Instructional Materials}

It was achieved by $88 \%(2.6 / 3)$ in the four courses (ARC404, ARC213, ARC302, and ARC211). The learners answered points 4.1, 4.2, 4.3 positively, which means that they achieved QM standard 4. The learners highlighted some weak points, such as Substandard point (4.4) The instructional materials represent up-to-date theory and practice in the discipline (33\%). Substandard point (4.5) A variety of instructional materials are used in the course (33\%). Figure 6 shows the results of standard 4. 


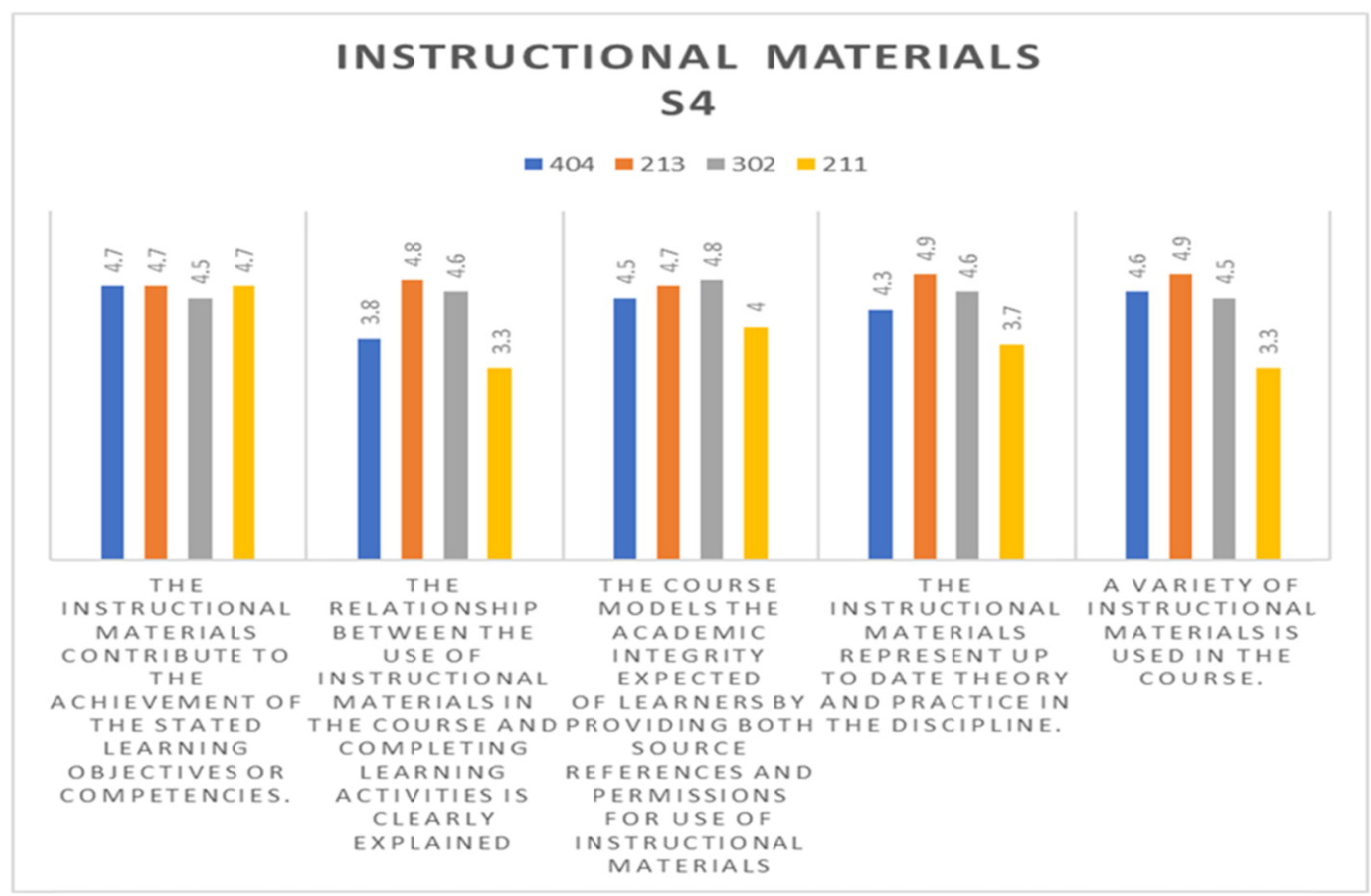

Figure 6. Evaluation of courses ARC404, ARC213, ARC302, and ARC211 for standard 4 in Quality Matter

\subsection{Standard 5: Learning Activities and Learner Interaction}

It was achieved by 83\% (2.5/3) in the four courses (ARC404, ARC213, ARC302, and ARC211). The learners answered points 5.2, 5.3, and 5.5 positively, which means they achieved QM standard 5. The learners highlighted some weak points, such as substandard point (5.1) learning activities promote the achievement of the stated learning objectives or competencies (33\%). In addition, substandard point 5.4 the requirements for learner interaction are clearly stated (33\%). Figure 7 shows the results of standard 5.

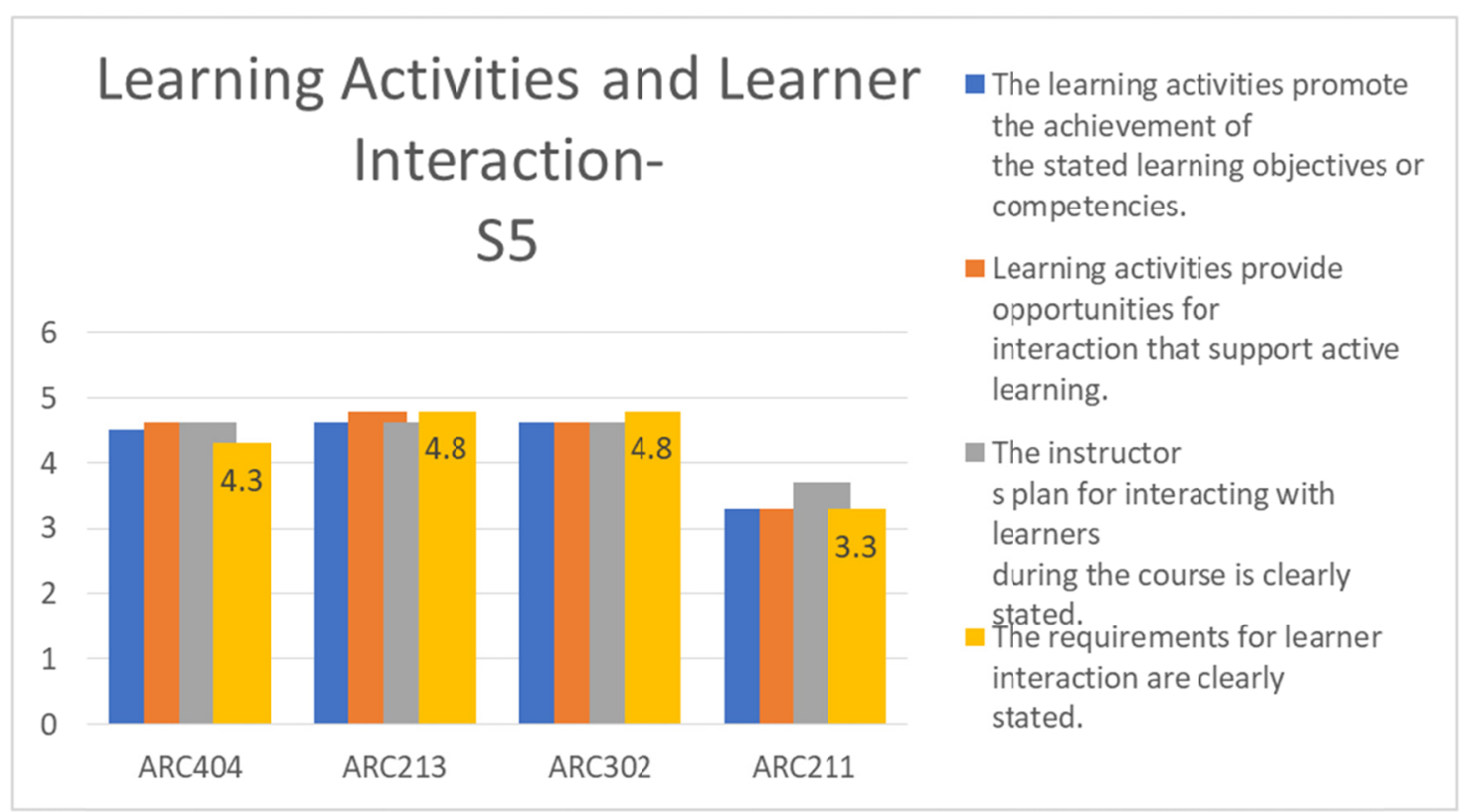

Figure 7. Evaluation of courses ARC404, ARC213, ARC302, and ARC211 for standard 5 in Quality Matter 3.6 Standard 6: Course Technology

It was achieved by 85\% (2.6/3) in the four courses (ARC404, (ARC213, (ARC302) and (ARC211). The learners answered point 6.4, which achieved the standard level in QM. The other three points will be discussed in the 
Discussion. The learner highlighted some weak points, such as Substandard point (6.1) the university gave tools help in teaching and learning. Also, substandard point (6.2) Course tools promote learner engagement and active learning. 6.3 the university is using variety of technologies in teaching. Figure 8 shows the results of standard 6 .

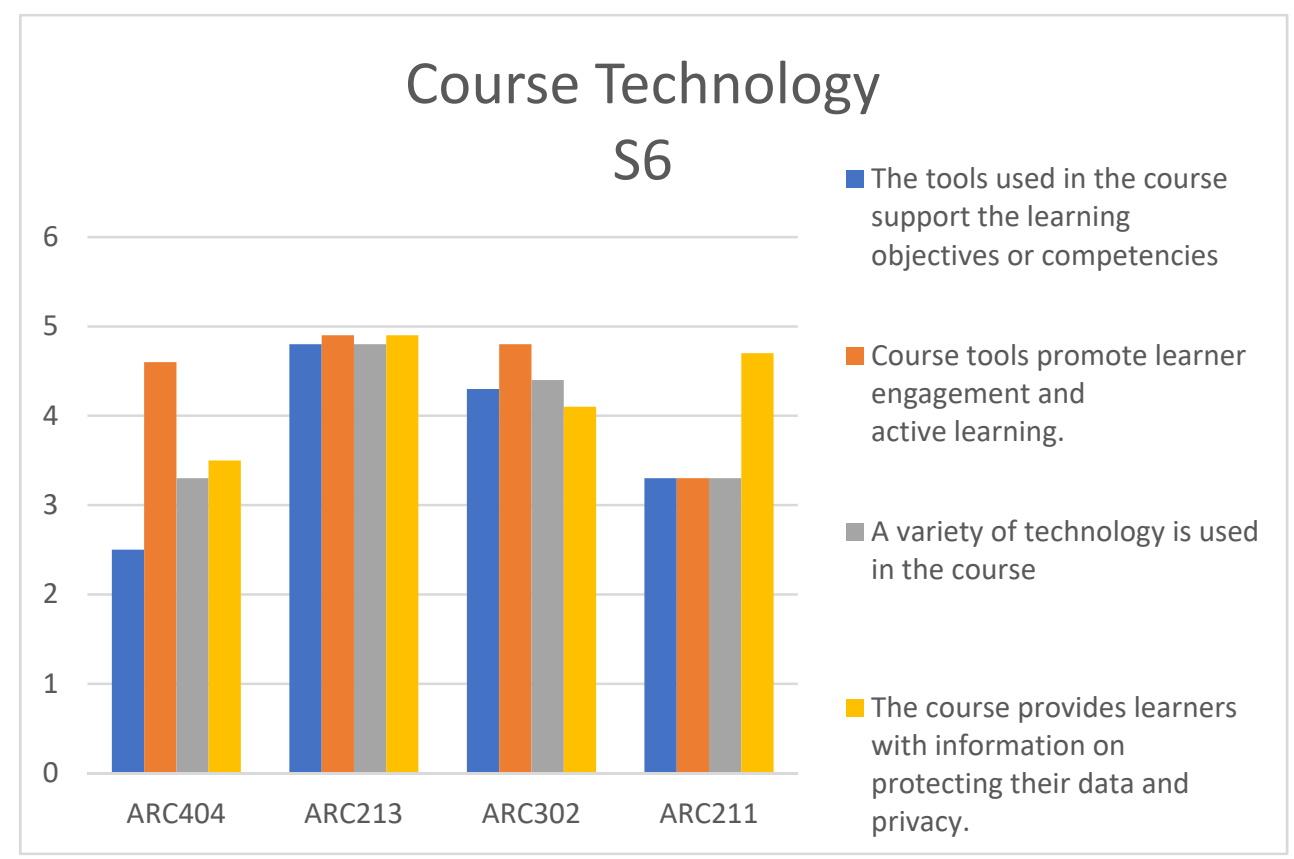

Figure 8. Evaluation of courses ARC404, ARC302, ARC213, and ARC211 for standard 6 in Quality Matter

\subsection{Standard 7: Learner Support}

Learning support was achieved by 87\% (2.6/3) in the four courses (ARC404, ARC213, ARC302, and ARC211). The learners answered points 7.2 and 7.4 positively, which means that they achieved QM standard 7. The learners highlighted some weak points, such as (7.1) the course instructions articulate or link a clear description of the technical support offered and how to obtain it (LMS manual). 7.3 course instructions articulate or link the institution's academic support services. Figure 9 shows the results of standard 7.

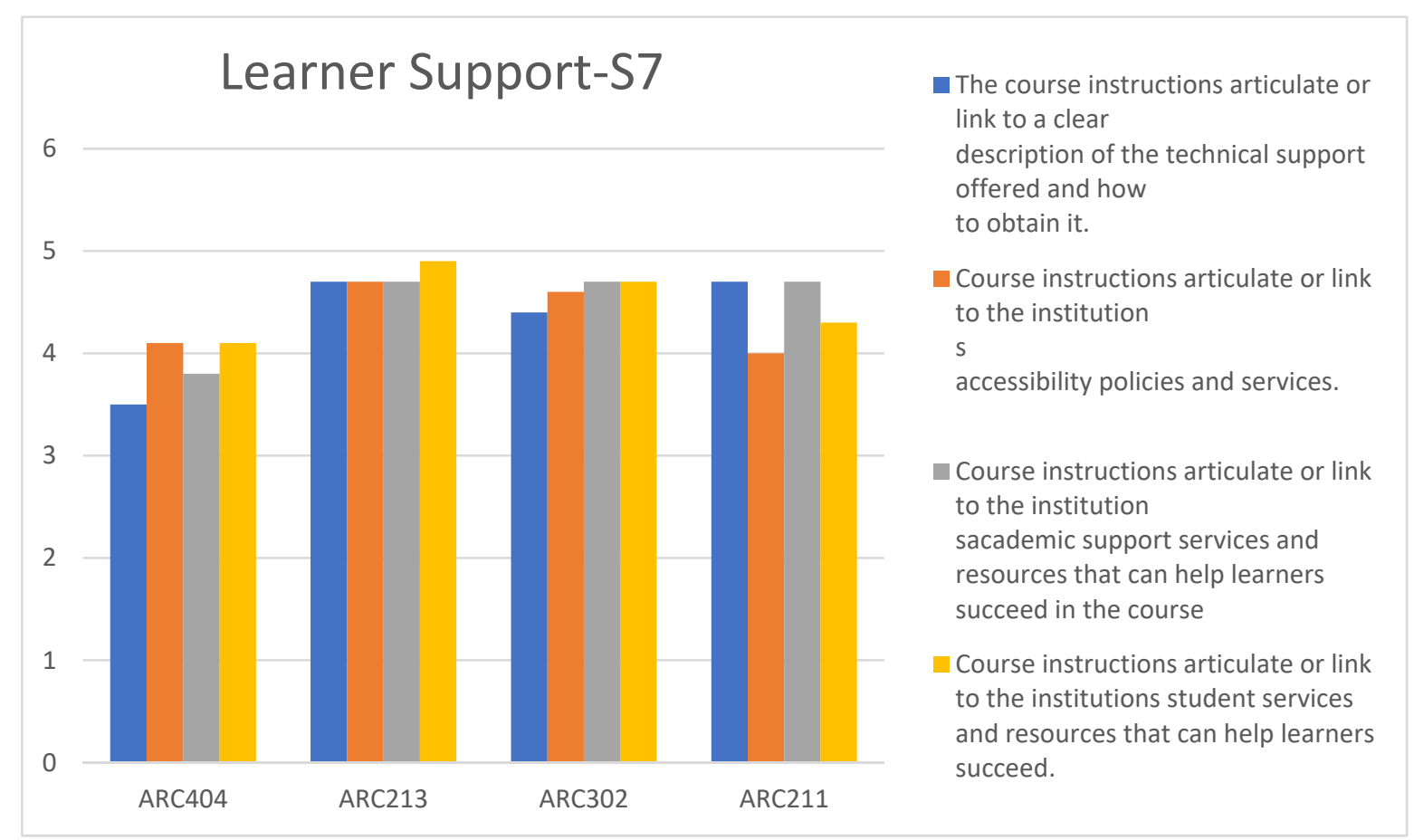

Figure 9. Evaluation of courses ARC404, ARC302, ARC213, and ARC211 for standard 7 in Quality Matter 


\subsection{Standard 8: Accessibility and Usability}

Accessibility was achieved by $89 \%$ (2.76/3) in the four courses (ARC404, ARC213, ARC302, and ARC211). The learners answered points 8.5 and 8.6 positively, which achieved the QM standard 8 learning outcome. The four other points will be discussed in the Discussion.

The learners highlighted some weak points, such as 8.1 course navigation facilitates ease of use (new LMS). 6.2 The course design facilitates readability. 8.3 The course provides accessible text and images in files, documents, LMS pages, and web pages to meet the needs of diverse learners (images). 8.4 the university is providing the WIFI for access to the (websites) 17\%. Figure 10 shows the results of standard 8.

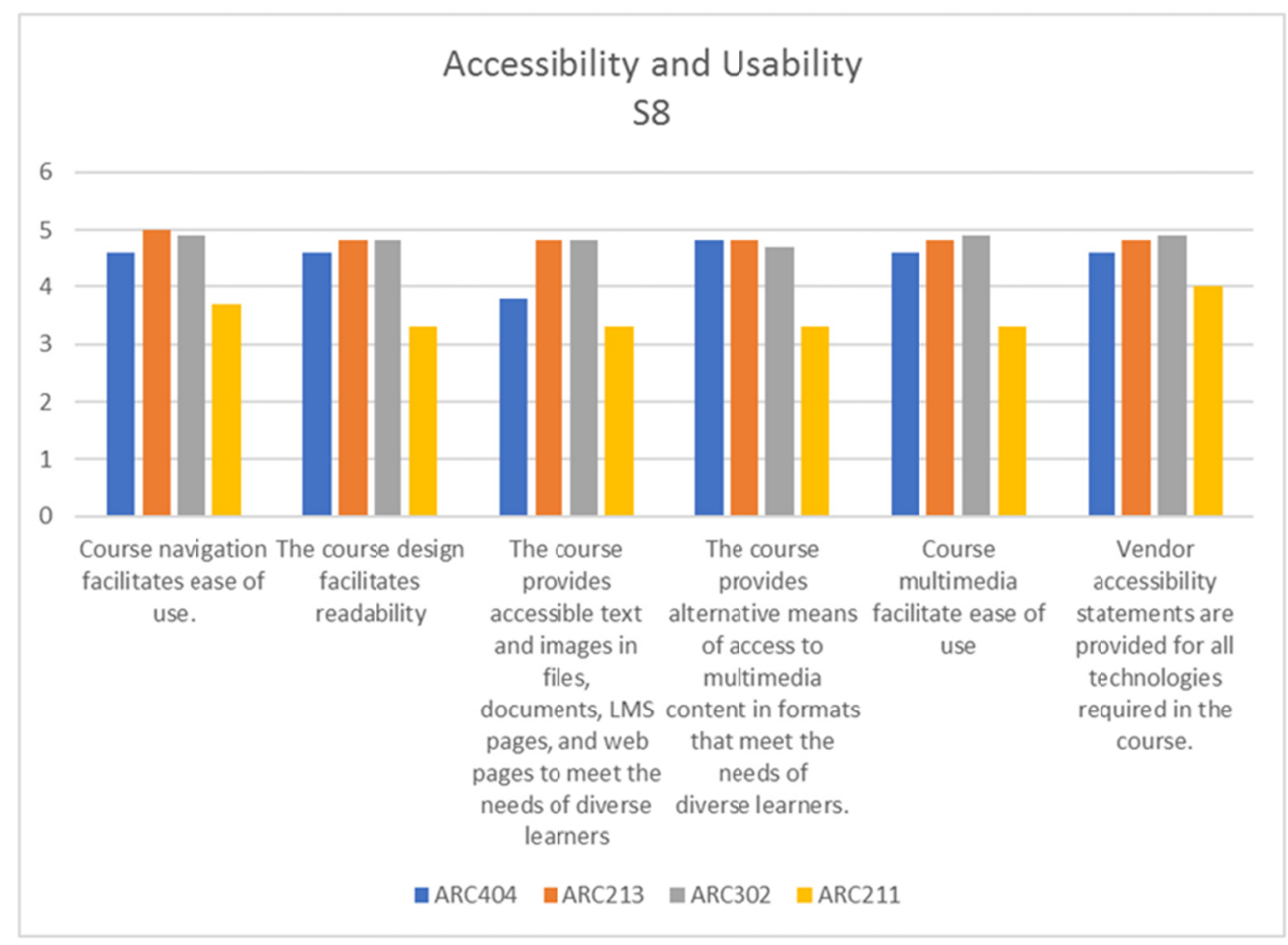

Figure 10. Evaluation of course ARC404, 302, 213, 211 by Quality Matter, S8

The average result is calculated for all the standards in the following table one response by the students the other response by the university quality unit. Table 2 shows the result by students, and Table 3 shows the result by the university.

Figure 11 shows the vibration in evaluation between the student and DAU Quality Unit, the students evaluate ARC 211 2.6/3, while the QU evaluate ARC211 2.8/3 in applying the QM standards this means that the response of student is not correct and it's based on personal feeling towards the course or the teacher, on the other hand, the QU evaluation is a professional evaluation based in the learning outcome and applying the QM standards. Figure 13 shows the evaluation by QU to all Architecture Eng. Courses which are range between $85 \%$ to $90 \%$, this means that most of the courses are achieved the QM standards, except 3 courses over 48 courses those will be focus on training program and improvement plan during this semester 2020-2021-2.

Table 2 . The results by the students

\begin{tabular}{llllllllll}
\hline & QM & QM & QM & QM & QM & QM & QM & QM & \multirow{2}{*}{ Total out of 3 } \\
& ST1 & ST2 & ST3 & ST4 & ST5 & ST6 & ST7 & ST8 & \\
\hline ARC404 & 3 & 2.73 & 2.73 & 2.61 & 2.7 & 2.1 & 2.3 & 2.7 & $2.6 / 3$ \\
$\mathrm{ARC} 13$ & 2.76 & 2.73 & 2.7 & 2.88 & 2.8 & 2.9 & 2.8 & 2.9 & $2.8 / 3$ \\
$\mathrm{ARC} 302$ & 2.7 & 2.64 & 2.64 & 2.76 & 2.76 & 2.64 & 2.8 & 2.9 & $2.7 / 3$ \\
$\mathrm{ARC} 11$ & 2.4 & 2.4 & 2.28 & 2.28 & 2.1 & 2.25 & 2.8 & 2.1 & $2.6 / 3$ \\
\hline
\end{tabular}


Table 3. The result by the university Quality Unit

\begin{tabular}{llllllllll}
\hline & QM & QM & QM & QM & QM & QM & QM & QM & \multirow{2}{*}{ Total out of 3 } \\
& ST1 & ST2 & ST3 & ST4 & ST5 & ST6 & ST7 & ST7 & \\
\hline ARC404 & - & - & - & - & - & - & - & - & $2.6 / 3$ \\
ARC213 & - & - & - & - & - & - & - & - & $2.6 / 3$ \\
ARC302 & - & - & - & - & - & - & - & - & $2.7 / 3$ \\
ARC211 & - & - & - & - & - & - & - & & $2.8 / 3$ \\
\hline
\end{tabular}

\section{Compare the results by the students to The results by The University Quality unit}

3

2.5

2

1.5

1

0.5

0
ARC404
ARC213
ARC302
ARC211
Student evalution
The university Quality Evaluation

Figure 11. The results between the University QU evaluation and the student's evaluation

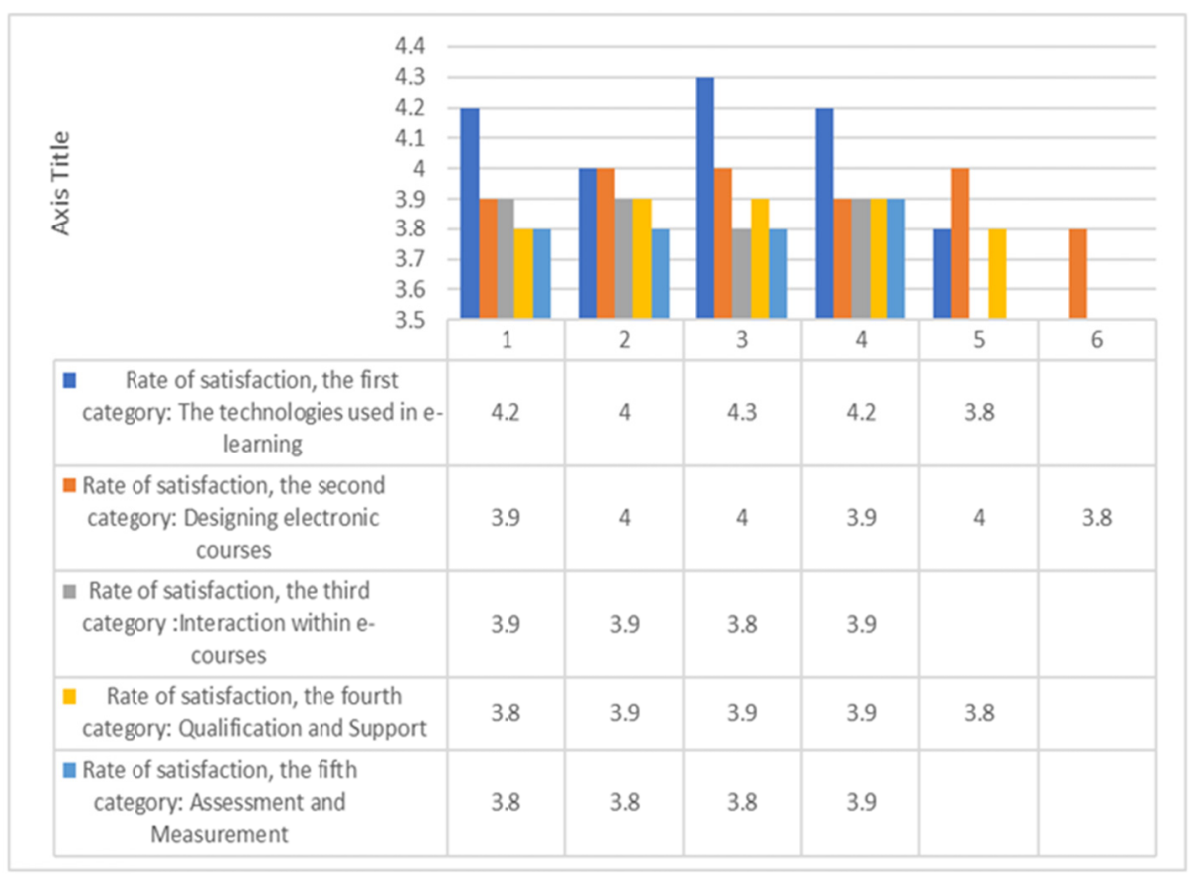

Figure 12. The results of the e-learning by The University QU and the Response of the Students for all courses in Architecture Engineering program, 20-21-1 


\section{Discussion}

Dar Al Uloom University recently started to apply the Quality Matter standards in all colleges, including the College of Architecture Engineering and Digital Design. The Quality Unit evaluates all the courses in the Student Learning System.

In this semester, 20-21-1, the researchers started to develop the course pages in the LMS following the QM checklist to achieve a high standard in e-learning.

The surveys were distributed to the students at the end of the semester during the period 30/11//2020 to 30/12/2020. The survey evaluated the following courses: Environmental Control, Theory of Architecture, History of Architecture, and Design Studio. A total of 73 students participated in courses ARC404, ARC302, ARC213, and ARC211. The survey included eight QM standards with questions in the standards. The learners highlighted some weak points that will be discussed. (Oyediran, 2020) and (Fauzi 2020) highlighted some problems facing least developed countries such as in Nigeria vis-_a-vis their socio-economic factors and limitations encountered and poor infrastructure and networking. In Saudi Arabia, the government offers Wi-Fi in 90\% (Mark, Th. 2021). In Saudi Arabia, all universities in public and private sectors areas offer the platform, there are some constraints in weakness on the internet sometimes, but it soon comes back and continued the online lectures.

\subsection{Course Overview}

The Architecture program follows Dar Al Uloom university policies and formulates its own policies for the students for registration, acceptance, attendance, evaluation criteria, teaching strategies, students' awards, and ethics. However, the teachers were not including the policies in the LMS.

Computer skills and digital information literacy skills expected from the learner are clearly stated. All the students learned computer skills in the primary year, which is basically learning for all disciplines. The Architecture program students studied AutoCAD and 3D Max in the second year.

Expectations for prerequisite knowledge in the discipline and/or any required competencies are clearly stated. Prerequisite knowledge is applied in the study plan. No student can register for the course unless he has passed the prerequisite course. This policy is clear to the students and is explained to them by their academic advisor and in the student handbook.

The course survey is clearly stated at the top of the course page in the LMS, and an introduction about the teacher's CV was given in the first lecture in the course.

\subsection{Learning Objectives (Competencies)}

The learning objectives or competencies are suited to the level of the course. Each course has a Course Learning Outcome (CLO). It is clearly stated in the course syllabus and course specification, and both were explained to the students in the first lecture (Introduction about the course). In the History of Architecture and Environmental Control courses, the required learning outcomes were verbal analysis and comparing, discussing, explaining, and drawing sketches. In the Design Studio course, the required skills include verbal critical thinking, solving the design problem, developing a design concept, designing 3D or model making, discussing in Joris, designing presentations, analyzing the site condition, and case studies in group work. All courses should apply the three main competencies (knowledge, skills, value). All the assignments should reflect the course competencies.

\subsection{Assessment and Measurement}

The researcher, Karin J. (2019), highlights the point the effect of assessment, interpretation, the credibility of assessment, on e-learning the student's response is positive to these variables.

The findings in this study show that the teacher provides a file for each assignment explaining and giving specific description criteria for the evaluation of the learner's work. The file is posted in the LMS near the lecture's files. Also, the course grading policy is written in the course syllabus, which is posted into the LMS and explained to the students in the first lecture.

The findings show that thirty-three percent of the learners stated that the course grading policy was not clear. The teacher should have a file for each course that is posted in the LMS clearly stating the grading policy; also, it is written in the course syllabus. Thirty-three percent of the learners stated that the specific and descriptive criteria provided for the evaluation of learners' work and their connection to the course grading policy did not clearly explain the procedures followed by the teacher. 


\subsection{Instructional Materials}

Thirty-three percent of the learners highlighted some weak points such as:

The instructional materials represent up-to-date theory. The law gives the teacher the ability to change $25 \%$ of the course materials, usually the teacher adding two new topics according to the market needs. Also, a variety of instructional materials are used in the course, including lectures, eBooks, lecture videos, useful website links, and YouTube. Figure 13 shows different teaching materials are used, such as lectures, lecture videos, teacher blogs, YouTube channels, and teacher websites.

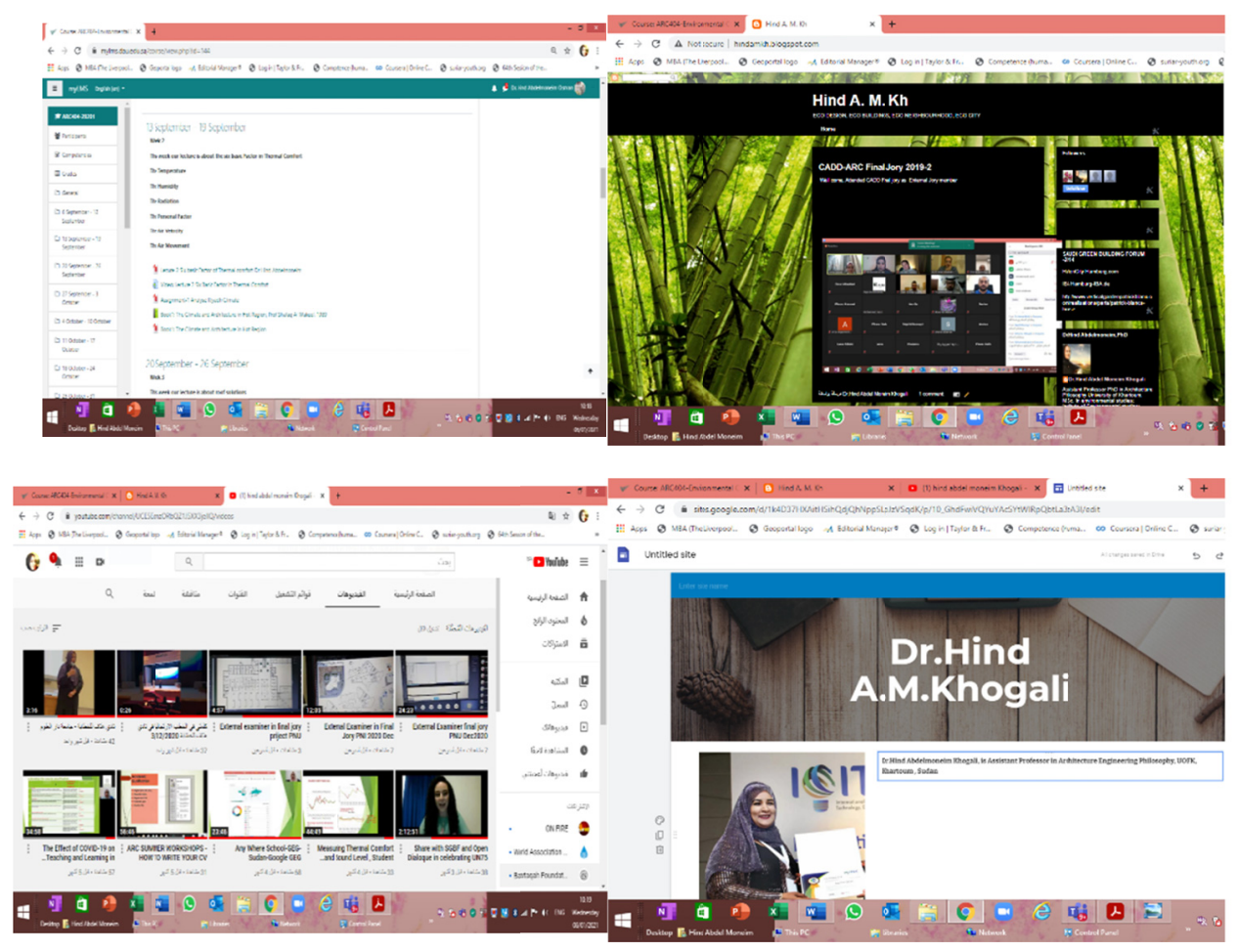

Figure 13. Different teaching materials used, such as Lectures, lecture videos, teacher blogger, teacher YouTube channel, and teacher website

\subsection{Learning Activities and Learner Interaction}

Thirty-three percent of the learners highlighted some weak points from the following:

Learning activities that promote the achievement of the stated learning objectives or competencies are not identified. Also, the teacher in the first lecture explained the course syllabus and course specification, both of which include the alignment of the assignments with the course learning outcome.

The teacher should prepare some questions for each lecture to ensure that all the students are engaged in the course activities. Some assignments are designed to be group work to encourage the students to interact with the course learning outcome. Various assignments and activities were designed to achieve course learning outcomes, such as analyzing case studies, analyzing project sites, comparing different pioneering principles or different history eras by comparative points, drawing sketches, designing 3D models, discussing group work, and discussing PowerPoint presentations. The value is achieved by teaching the student the responsibility of uploading the assignments at a specific time, submitting the course file, and group work and team leadership. Knowledge is achieved and tested in the midterm, final exams, and questionnaires.

\subsection{Course Technology}

Goda (2020) highlighted the importance of technology and online learning platforms have become an essential part of the educational process, learner support, workshops, and interactive learning. Another point was highlighted by Vaid (2020) to use the artificial intelligent in teaching and learning as new technology Also Mammadova, I. (2020) highlights the point of using different technologies. In this research Twenty-two percent of the learners highlighted some positive points from the following:

The teacher used different tools to help the learner apply their assignments and achieve the learning outcome. 
Apply of the Microsoft Teams program gives the teacher and the students the ability to present the lectures online and to listen, speak and discuss during the lecture, use of the whiteboard, and smartboard are used in Microsoft Teams. The Student Management System (LMS). The Lecture videos: usually, the teacher records the lecture and posts it in the LMS. Also, the teacher's YouTube channel. The teacher recorded additional information for the students. Also, support method could be the teacher's website, screens from the students are shared to explain their project; the 3D model of the project that is used in the design projects is explained online; virtual lectures are used. The students attended virtual lectures with Prince Sultan University; virtual conferences are used to help the students attend the virtual forum with Ach-Net. Teacher blogger can support course new technologies. Figure 14, shows different course technologies (a-d). Some learning tools are not used such as virtual sites, virtual visits, virtual reality, and virtual labs.

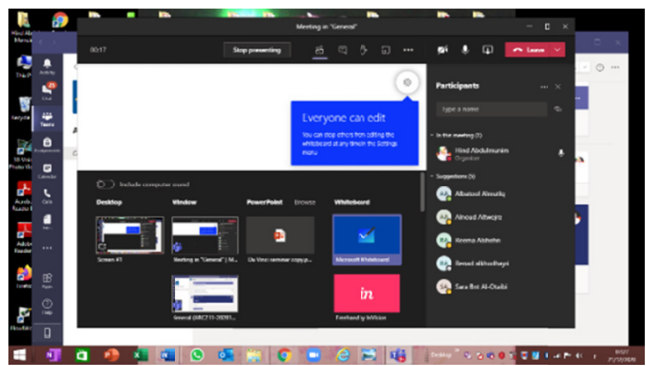

(a) Microsoft Teams

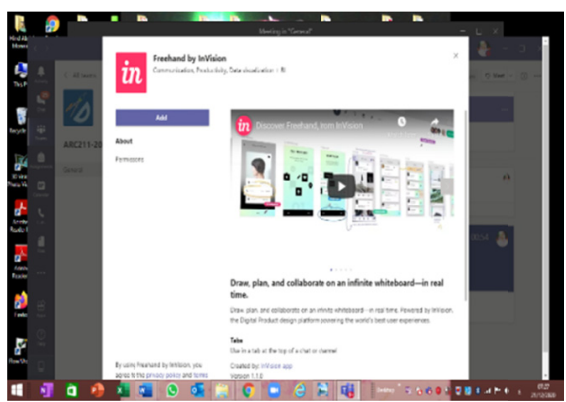

(c) The envision

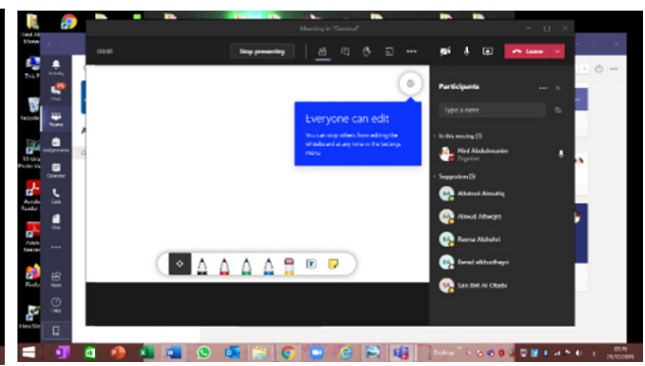

(b) Whiteboard

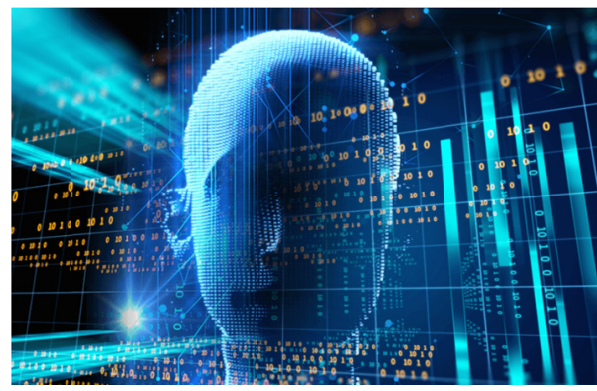

(d) Virtual Reality

Figure 14. Different course technologies (a-d). Some learning tools are not used such as virtual sites, virtual visits, virtual reality, and virtual labs

\subsection{Learner Support}

Thirty-three percent of the learners highlighted some weak points from the following:

IT unit at Dar Al Uloom University offered an orientation workshop to the students and teachers at the beginning of the semester about SIS and LMS. An orientation email was sent by the IT unit to the students and teachers about LMS enrolment. An orientation email was sent by IT about how to secure a user password. An orientation email was sent by IT about online exams. An orientation email was sent by IT about how to secure your email from hackers. DAU measured the user responses towards the services at the end of each semester to improve the IT services. Accessibility to DAU WIFI is available for students and teachers. Projectors and data platforms are available. The teacher provided the IT support phone, email, and office location in one fille and posted it for each course. A digital library is available for the students and the teachers. Figure 15 shows the IT support by email (a), in the University platform (b), the Digital library (c), and the LMS, SIS (d). 


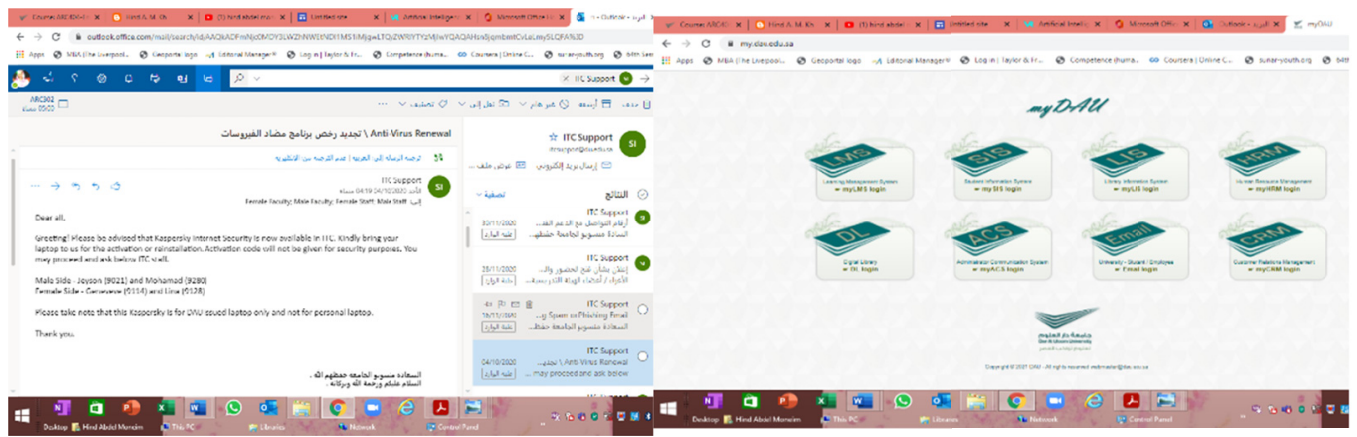

(a) The email

(b) The platform

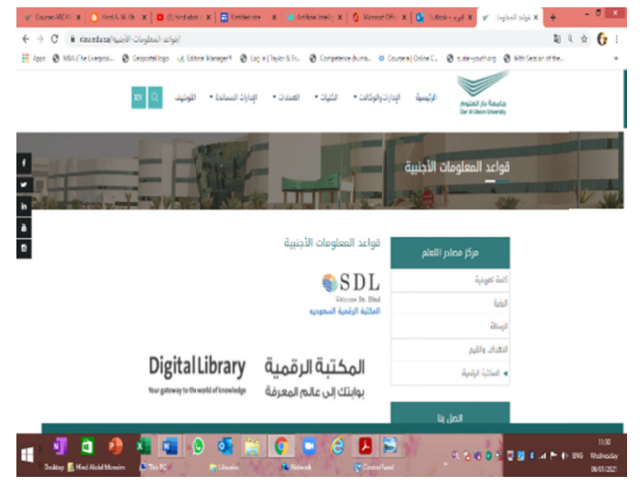

(c) The Digital Library

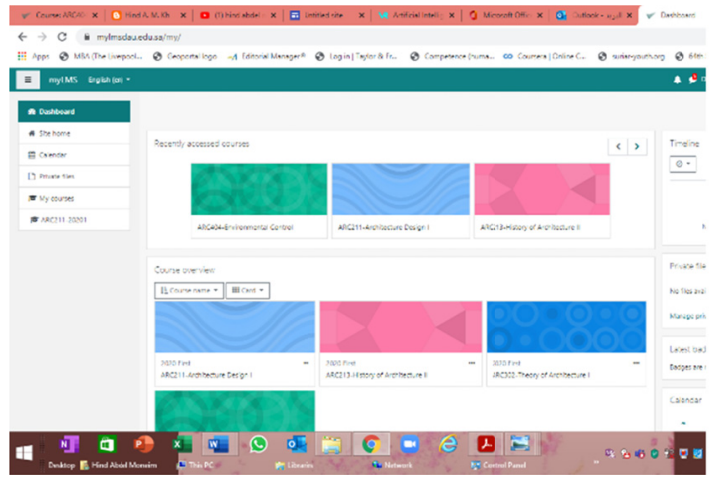

(d) The LMS

Figure 15. The IT support by email (a), in the University platform (b), the Digital library (c), and the LMS, SIS

\subsection{Accessibility and Usability}

The research found that seventeen percent of the learners highlighted some weak points from the following:

Course navigation facilitates ease of use (new LMS). The course design facilitates readability and was explained to the teachers and students in workshops at the beginning of the semester. The LMS manual needs to provide accessible text and images in files, documents, LMS pages, and web pages to meet the needs of diverse learners (images) Daniel C. (2020) and QM (quality matter, 2020) encourage to develop the of the digital platform.

The research outcome shows difference in results in the learning outcomes. The workshops were recorded as videos in Microsoft Teams and were provided to the learners. The results from DAU QU are compared with the results from the students. Figure 11 shows the results between the DAU QU and the students.

The results for ARC404 showed the same response of 2.6/3 by the DAU QU and the Students. ARC302 also had the same result and evaluation by DAU QU and the students. There was a slight differentiation in the results of ARC213: the DAU QU evaluated the course lower than the students, 2.6/3, while the students evaluated it at 2.8/3. For ARC211, the DAU evaluated the course higher than the students, at 2.8/3, while the students evaluated it at 2.6/3.

In assessing the quality of work and if it was presented in LMS to the students, two remarks were received from the Quality Unit: one about the policies not being pasted in LMS and the second about ARC213 needing more details for the students. From the students' point of view, they evaluated the course in terms of personal impact from the teacher and the difficulties in the course; if they found the course easy for them, they gave a high impact. If the course was difficult for them, they gave a lower impact. Figure 16 shows the results of the e-learning and teaching by The University QU for all courses in Architecture Engineering. Program 20-21-2. 


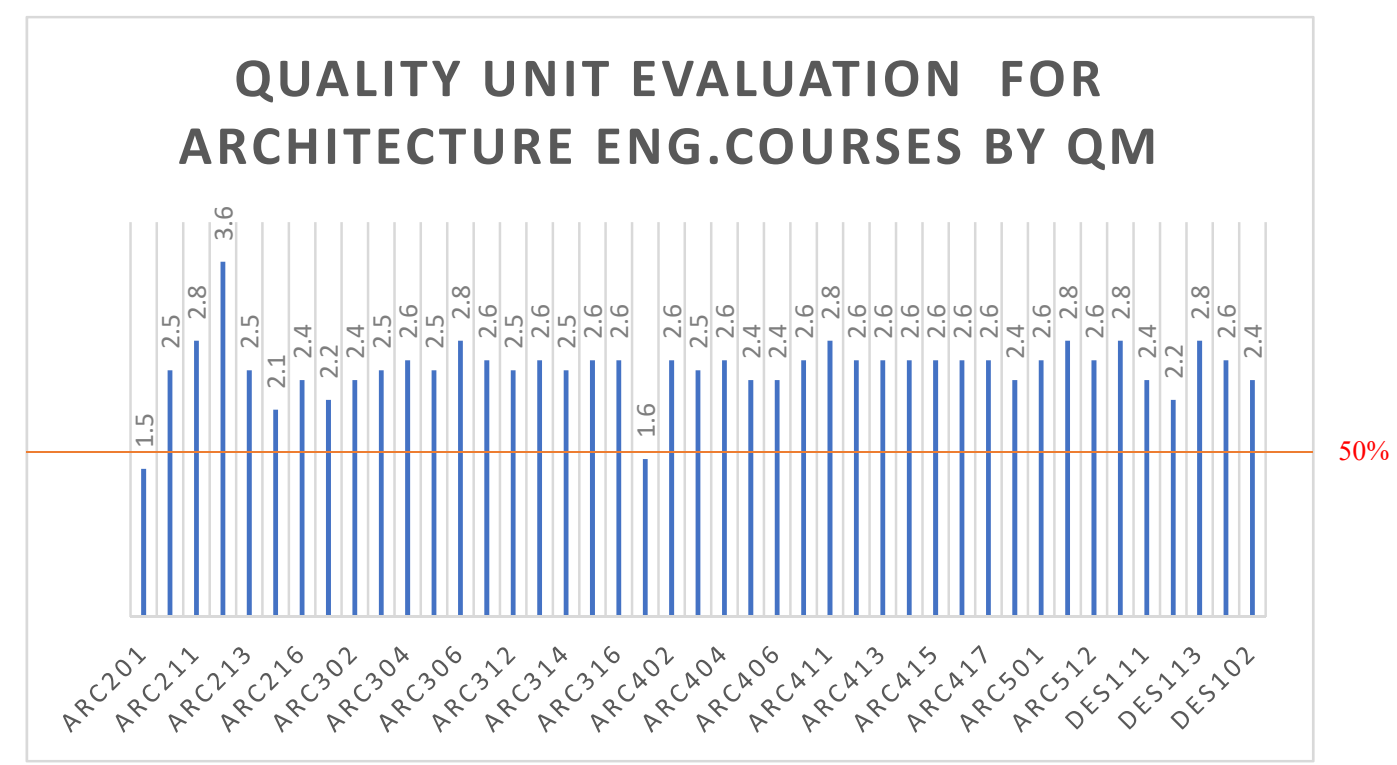

Figure 16. The results of the e-learning and teaching by The University QU for all courses in Architecture Engineering. Program 20-21-2.

The first hypothesis the LMS apply the Quality matter standards

The university Quality Unit is applying the Quality Matter evaluation to all Architecture courses see figure 16.

Ansering the second hypothes all the e-courses are passed the evaluation by $95 \%$ only $5 \%$ (2 courses) not pass Figure 16.

Answering the third hypothes The improvement plan for those courses (5\%) of total courses is to offer them training workshops by the quality unit.

\section{Conclusions}

The research recommends that posting the policies in the LMS as a PDF file or in the Students' Manual, and demonstrate the computer skills needed in the course for the course since the course is delivered online. The student needs to apply his/her knowledge in computer skills in the proper way. In addition, the research recommends that the teacher should explain the prerequisite knowledge in the discipline and/or any required competencies to the students, such as writing, analysing, drawing sketches, working in groups, and discussing in design juries.

The research recommends that the teacher should write an introduction about him/herself in the LMS, mentioning their email, phone and office phone numbers, and office hours. Additionally, a video about the CV can be uploaded. Also, the teacher should ensure that the assignment suits the learning outcomes. In addition, the course should demonstrate the required knowledge skills and values according to the PLO and the CLO. Additionally, they should ensure that all the assignments reflect the learning outcome.

Assessment and measurement criteria should be clearly explained to the student in the course syllabus.

The course material should be updated regularly by $25 \%$ according to the market needs.

A variety of teaching materials should be used, such as lectures, lecture videos, eBooks, teacher websites, teacher blogs, and YouTube teacher channels. The variety of learning activities and learner interaction should be explained to the students at the beginning of the semester, and what the teacher is expecting from the students in each assignment and activity should be clearly explained. The teacher should be sure that course tools promote learner engagement and active learning. Tools such as teacher websites, blogs, YouTube channels, smartboards, whiteboards, and 3D project discussions should be provided online.

The teacher should use a variety of technologies in the course, such as virtual site visits, virtual building visits, virtual reality, and virtual labs.

Learner support should be offered, such as IT support, digital library, WIFI, data, IT support for the final exam, LMS support, SIS support, and email support. The course navigation facilitates ease of use (new LMS). The 
course design facilitates readability and should be explained to teachers and students through workshops at the beginning of the semester.

LMS manual should be provided. Accessibility to LMS should be suitable to the teachers and the students.

Course resources should include alternative means of access to multimedia content in a format that meets the needs of diverse learners. The workshops should be recorded as videos and given to the learners.

Last, the teaching and learning procedures should be from the heart of the teacher to the mind of the students to ensure that the course achieves the QM learning outcome standards and provides a human sense to the students during this period of COVID-19.

The students should share in the interactive learning by applying different teaching strategies such as PowerPoint presentation, reverse learning, groupwork discussion, design Jory discussion, evaluate their work, etc.

\section{Suggestions for Future Research}

1) Using different technologies in e-learning and teaching

2) Using different teaching strategies in e-learning in Architecture program

\section{Acknowledgement}

The author would like to acknowledge Dar Al Uloom University, and its Deanship of Post-graduate studies and Scientific Research for funding this research. Appreciation should be extended to the Dean of CADD, and the ARC Research Committee.

\section{References}

ABET. (2019). CRITERIA FOR ACCREDITING ENGINEERING PROGRAMS. USA: Copyright (C) 2018 by ABET. Retrieved from https://www.abet.org/wp-content/uploads/2015/10/E001-16-17-EAC-Criteria-10-20-15

Alizadeh, M. (2019). Evaluating a blended course for Japanese learners of English: why Quality Matters. International Journal of Educational Technology in Higher Education, 16. https://doi.org/10.1186/s41239-019-0137-2

Daniel, C. (2020). Innovative Teaching and Learning Process during COVID 19. In A. S. Thomas (Ed.), Innovative Teaching and Learning Process during COVID 19 (pp. 1-80). Kerala Agricultural University, INDIA.

DAU. (2021). Quality Standards for E Courses. Riyadh City, Saudi Arabia Kingdom.

Education, Swedisn NationalAgency for Higher. (2008). E-learning quality Aspects and criteria for evaluation of e-learning in higher education. Swidish: Swedisn National Agency. Retrieved from https://scholar.google.com/scholar?q=E-learning + quality + Aspects + and + criteria + for + evaluation + of + e-learn ing + in + higher+education\&hl $=$ ar\&as_sdt $=0 \&$ as_vis $=1 \&$ oi $=$ scholart

ETEC. (2020). National Engineering Learning Outcomes. KSA: Engineering Learning Outcomes Committee, National Qualifications Framework, ETEC.

Fauzi, Irfan. (2020). Teachers' Elementary School in Online Learning of COVID-19. Journal Iqra, 5(1). https://doi.org/10.25217/ji.v5i1.914

Ghobrini, R. E. (2020). Synergizing Facebook and YouTube for e-Teaching Grammar during Covid-19. International Journal of Research in Education and Science. https://doi.org/10.26697/ijes.2020.4.8

Goda, Nesrin. (2020). COVID-19 AND ONLINE TEACHING IN HIGHER EDUCATION: A CASE STUDY OF PRIVATE COLLEGES - SAUDI ARABIA. International Journal Of English and Studies (IJOES), 2(10). Retrieved

from https://www.researchgate.net/publication/345898419_COVID-19_AND_ONLINE_TEACHING_IN_HIGH ER_EDUCATION_A_CASE_STUDY_OF_PRIVATE_COLLEGES_-SAUDI_ARABIA

https://www.qualitymatters.org/sites/default/files/research-docs-pdfs/2019-K-12-Dissertation-Literature-Review. pdf

IEA. (2007). How do we build mutual understanding among nations about the quality of engineers who enter the globally connected workplace? UK: Washington Accord. Retrieved from https://www.ieagreements.org/accords/washington/ 
Jassim, L. L. (2020). Using E-Learning Technologies in Teaching and Learning Process. International Journal of Social Learning, 1(1). https://doi.org/10.47134/ijsl.v1i1.1

Khogali, Hind. (2020). The Effect of COVID-19 CORONA VIRUS on Sustainable Teaching and Learning in Architecture Engineering. Journal of Applied Science, 14(8). https://doi.org/10.5539/mas.v14n8p44

Mammadova, I. (2020). TEACHING WITH TECHNOLOGY, LEARNING BY DESIGN. Bulletin of Science and Practice, 6(12). https://doi.org/10.33619/2414-2948/61/52

Mark, Th. (2021). The Effect of CORONA on Teaching and Students in Saudi Arabia. King Faisal Center for Research, and Islamic Studies. Saudi Arabia.

Mark, Th. (2021). The Kingdom's Response to the COVID-19 Outbreak: Steps That Have Been Taken to Date. King Faisal Center for Research, and Islamic Studies. Saudi Arabia.

Matter, Q. Q. (2020). Grounded in research. Driven by best practices. A community that puts learners first. Retrieved from https://www.qualitymatters.org

Mseleku, Z. (2020). A Literature Review of E-Learning and E-Teaching in the Era of Covid-19 Pandemic. International Journal of Innovative Science and Research Technology, 5(10). Retrieved from https://www.researchgate.net/publication/344927168

Oyediran, Wasiu Oyeleke. (2020). Prospects and limitations of e-learning application in private tertiary. Heliyon, 6(11). https://doi.org/10.1016/j.heliyon.2020.e05457

QM. (2019). Quality Matter. Higher Education Literature Review Summary. DAU. Quality Standards for ECourses. Riyadh City, Saudi Arabia Kingdom, KSA. Retrieved from https://www.qualitymatters.org/sites/default/files/research-docs-pdfs/2019-Higher-Education-Literature-Re view-Summary-Report.pdf

QM. (2020). Grounded in research. Driven by best practices. A community that puts learners first. Retrieved from https://www.qualitymatters.org/

QM. (2020). quality matter. Administrative Supports for Digital Accessibility: Policies and Processes: quality matter.org

QM. (2021). Quality Matter. Quality Matter Checklist: quality matter.org

Sadaf, A. (2019). Student Perceptions of the Impact of Quality Matters-Certified Online Courses on Their Learning and Engagement. Online Learning Journal. https://doi.org/10.24059/olj.v23i4.2009

Sharma, A. (2017). Learning Management System for Virtual Teaching and Learning. World Academics Journal of Engineering Science, 4(1), 5-7. Retrieved from https://www.researchgate.net/publication/345983706

Shattuck, Barbra Burch, \& Kay. (2019). QM K-12 Online Learning Research. QM Research and Development, $1-10$.

Sireesha1, N. (2020). Teaching to Learn or Learning to Teach-? A Review on LMS. TEST Engineering and Management. Retrieved from https://www.researchgate.net/publication/344388068

Sultana, Nosaiba. (2020). E-Learning: Covid19 Pandemic: Impact and strategies for education sector in India. International Journal of Creative Research Thoughts (IJCRT). Retrieved from https://www.researchgate.net/publication/348786049_E-Learning_Covid19_Pandemic_Impact_and_strategi es_for_education_sector_in_India

Vaid, Shashank. (2020). Deep learning COVID-19 detection bias: accuracy. International Orthopaedics, 44. https://doi.org/10.1007/s00264-020-04609-7

Webinar, Sudanes Research Foundation. (2020). The Effect of COVID-19 in Teaching and Learning in Architecture Engineering Colleges. YouTube. 20 Sat. June. Retrieved from https://www.youtube.com/watch?v=ehp0Ufis-QI\&t=6s 


\section{Appendix}

Table 1. Shows the applied assessment method by QM checklist on this research with 5 points of evaluation

\begin{tabular}{lllllll}
\hline & $\begin{array}{l}\text { Strongly } \\
\text { Agree }\end{array}$ & Agree & Average & Disagree & $\begin{array}{l}\text { Strongly } \\
\text { Disagree }\end{array}$ & $\begin{array}{l}\text { The Average } \\
\text { Result for the } \\
\text { Question }\end{array}$ \\
\hline $80-100$ & $70-80$ & $50-70$ & $40-30$ & $30-1$ \\
& $5 / 5$ & $4 / 4$ & $3 / 3$ & $2 / 2$ & $1 / 1$ \\
404 & 213 & 302 & 211 &
\end{tabular}

1) Course Overview and Introduction

Instructions made clear; how

1.1 to get started and where to

find various course components.

Learners are introduced to

1.2 the purpose and structure of the course.

Communication

expectations for online

1.3 discussions. Email and other forms of interaction are clearly stated.

Courses and institutional policies with which the learner is expected to

1.4 comply are clearly stated within the course, or a link to current policies is provided.

Minimum technology requirements for the course

1.5 are clearly stated, and information on how to obtain the technologies are provided.

Computer skills and digital

1.6 information literacy skills expected of the learner are clearly stated.

Expectations for prerequisite and knowledge in the

1.7 discipline and/or any required competencies are clearly stated.

The self-introduction of the

1.8 instructor is professional and is available online.

Learners are asked to

1.9 introd. 
2) Learning Objectives (Competencies)

The course learning

objectives, or

2.1 course/program $\begin{aligned} & \text { competencies describe } \\ & \text { coutcomes }\end{aligned}$

outcomes that are

measurable.

The module/unit level

learning objectives or competencies describe

2.2 outcomes that are measurable and consistent with the course level objectives or competencies.

Learning objectives or competencies are stated

2.3 Clearly, written from the learner's perspective, and prominently located in the course.

The relationship between learning objectives / competencies and learning activities are clearly stated.

The learning objectives or

2.5 competencies are suited to the level of the course.

3) Assessment and Measurement

The assessments measure

3.1 the achievement of the stated learning objectives or competencies.

The course grading policy is

3.2 stated clearly in the beginning of the course.

Specific and descriptive criteria are provided for the

3.3 evaluation of learners' work, and their connection to the course grading policy is clearly explained.

The assessments used are

3.4 sequenced, varied, and suited to the level of the course.

The course provides learners with multiple opportunities to track their learning 3.5 progress with timely feedback. 
4) Instructional Materials

The instructional materials contribute to the

4.1 achievement of the stated learning objectives or competencies.

The relationship between the use of instructional materials

4.2 in the course and completing learning activities is clearly explained.

The course models the academic integrity expected

4.3 of learners by providing both source references and permissions for use of instructional materials.

The instructional materials represent up-to-date theory and practice in the discipline.

A variety of instructional

4.5 materials is used in the course.

5) Learning Activities and Learner Interaction

The learning activities promote the achievement of the stated learning objectives or competencies.

Learning activities provide

5.2 opportunities for interaction that supports active learning.

The instructors plan for

5.3 interacting with learners during the course is clearly stated.

5.4 The requirements for learner interaction are clearly stated.

6) Course Technology

The tools used in the course

6.1 support the learning objectives or competencies.

Course tools promote learner

6.2 engagement and active learning.

6.3 A variety of technology is used in the course.

The course provides learners with information on protecting their data and privacy. 


\section{7) Learner Support}

The course instructions articulate or link a clear

7.1 description of the technical support offered and how to obtain it.

Course instructions articulate or link the institutions accessibility policies and services.

Course instructions articulate or link the institutions academic

7.3 support services and resources that can help learners succeed in the course.

Course instructions articulate or link the

7.4 institutions student services and resources that can help learners succeed.

8) Accessibility and Usability

8.1 Course navigation facilitates ease of use.

8.2 The course design facilitates readability

The course provides accessible text and images in

8.3 files, documents, LMS pages, and web pages to meet the needs of diverse learners.

The course provides alternative means of access

8.4 to multimedia content in formats that meet the needs of diverse learners.

8.5 Course multimedia facilitate ease of use.

Source: designed by the researcher.

\section{Copyrights}

Copyright for this article is retained by the author(s), with first publication rights granted to the journal.

This is an open-access article distributed under the terms and conditions of the Creative Commons Attribution license (http://creativecommons.org/licenses/by/4.0/). 